\title{
Effectiveness of peer support for improving glycaemic control in patients with type 2 diabetes: a meta-analysis of randomized controlled trials
}

\author{
Li Qi ${ }^{1,2}$, Qin Liu ${ }^{3}$, Xiaoling $\mathrm{Qi}^{4}$, Na Wu${ }^{1}$, Wenge Tang ${ }^{2}$ and Hongyan Xiong ${ }^{1 *}$
}

\begin{abstract}
Background: To assess the effects of peer support at improving glycemic control in patients with type 2 diabetes.

Methods: Relevant electronic databases were sought for this investigation up to Dec 2014. Randomized controlled trials involving patients with type 2 diabetes that evaluated the effect of peer support on glycated hemoglobin (HbA1c) concentrations were included. The pooled mean differences (MD) between intervention and control groups with 95\% confidence interval (Cl) were calculated using random-effects model. The Cochrane Collaboration's tool was used to assess the risk of bias.

Results: Thirteen randomized controlled trials met the inclusion criteria. Peer support resulted in a significant reduction in HbA1c (MD -0.57 [95\% Cl: -0.78 to -0.36$]$ ). Programs with moderate or high frequency of contact showed a significant reduction in HbA1c levels (MD -0.52 [95\% Cl: -0.60 to -0.44 ] and -0.75 [95\% Cl: -1.21 to -0.29$]$, respectively), whereas programs with low frequency of contact showed no significant reduction (MD -0.32 [95\% Cl: -0.74 to 0.09$]$ ). The reduction in $\mathrm{HbA1c}$ were greater among patients with a baseline $\mathrm{HbA} 1 \mathrm{c} \geq 8.5 \%(\mathrm{MD}-0.78$ [95\% Cl: -1.06 to -0.51$])$ and between $7.5 \sim 8.5 \%$ (MD -0.76 [95\% Cl: -1.05 to -0.47$]$ ), than patients with $\mathrm{HbA} 1 \mathrm{c}<7.5 \%$ (MD -0.08 [95\% Cl: -0.32 to 0.16$]$ ).

Conclusions: Peer support had a significant impact on $\mathrm{HbA}_{1 c}$ levels among patients with type 2 diabetes. Priority should be given to programs with moderate or high frequency of contact for target patients with poor glycemic control rather than programs with low frequency of contact that target the overall population of patients.
\end{abstract}

Keywords: Peer support, Randomized control trial, Type 2 diabetes, Meta-analysis

\section{Background}

Diabetes (predominantly type 2 diabetes) ranks highly on the international health agenda as a global pandemic and as a threat to human health and global economies $[1,2]$. The self-management of diabetes, involving lifestyle modifications such as improving diet, increasing physical activity, self-monitoring of health status (blood glucose and examination of feet) as well as adherence to medication regimens, are key to improving outcomes in diabetes [3].

Specialist nurses and diabetes educators are being used to promote diabetes self-management [4-6], but such

\footnotetext{
*Correspondence: qili19812012@126.com

'Department of Military Epidemiology, College of Military Prevention, Third Military Medical University, Chongqing, China

Full list of author information is available at the end of the article
}

programs are resource intensive, the numbers of specialist nurses and diabetes educators are not adequate to carter for the increasing demand for diabetes care, especially in low-resource settings $[7,8]$. Therefore, it is urgent to find innovative and effective solutions that build on available resources to help patients successfully manage diabetes.

Currently, growing evidence suggests that peer support offers a promising solution. Peer support has been defined as 'support from a person who possesses experiential knowledge of a specific behavior or stressor and similar characteristics as the target population [9]. Peer support helps reduce or prevent problematic health behaviours [10,11], vascular disease [12], HIV [13,14], Parkinson's disease [15], etc. The success of peer support appears to be due in part to the nonhierarchical, reciprocal relationship that is created through the 
sharing of similar life experiences [9], and psychosocial processes that may be important in peer support including social support, experiential knowledge, and those described by social learning theory, social comparison theory and the helper-therapy principle [16]. Equally important, by training and employing non-professional staff members, peer support seems to be much less resourceintensive than traditional case management models. Therefore, it has been hypothesized that peer support could be considered as an alternative for diabetes selfmanagement education and on-going support programs and tackling the burden of diabetes. To date, studies on the effect of peer support on patients with diabetes have shown inconsistent results $[17,18]$.

Several reviews have been conducted, but these are focused solely on one type of peer support, such as that from a community health worker [19], volunteer-based peer support [20] or telephone peer support intervention [21], neither of which included randomized controlled trials (RCTs) [19-22] or quantitative analysis [23,24].

Consequently, we conducted a meta-analysis of RCTs to evaluate the effect of peer support on glycemic control among patients with type 2 diabetes (T2DM), which accounts for $90-95 \%$ of all diagnosed cases of diabetes. The results will facilitate the planning of evidence-based programs and will help inform future research.

\section{Methods}

This meta-analysis is reported following the criteria of PRISMA statement [25] and was approved by ethical committee of research in Chongqing Municipal Center for Disease Control and Prevention.

\section{Data sources and searches}

An extensive MEDLINE (from 1978 to Dec 2014), EMBASE (1980 to Dec 2014) and Cochrane Collaborative database (up to Dec 2014) were sought for RCTs based on the following search terms: peer supportrelated terms ('peer', 'promoters', 'patient navigators', 'lay health workers', 'community health worker', 'peer educator', 'peer mentor', 'lay health leader', 'peer support' and 'natural helpers') and diabetes-related terms ('diabetes mellitus', 'T2DM', 'Glycosylated hemoglobin', 'HbA1c', and 'NIDDM').

\section{Inclusion criteria and outcomes}

Studies were considered eligible for the meta-analysis if they met the following inclusion criteria: 1) RCTs, because this study design has maximum validity and causal inference [26]; 2) adults (aged $\geq 18$ years) diagnosed with T2DM; 3) studies that reported HbA1c levels, which is an index of the mean blood glucose concentration of the preceding 8-12 weeks and is the recommended index for evaluation of glycemic control of diabetes [27]; 4) peer support represented the majority of the interventions; 5) compared with a usual or routine care group.

Studies were excluded if they met one of the exclusion criteria: 1) the intervention was delivered by a health care professional; 2) the intervention did not involve direct contact between peer supporters and patient or was unclear; 3) non-English language publications.

\section{Methods of the review}

Abstracts of cited articles were evaluated by two independent reviewers (QL \& QXL) to determine the relevance, with differences resolved by a third reviewer (XHY) where necessary. When studies appeared to meet all the inclusion criteria, but data was incomplete, we contacted authors for additional data or clarification. Whenever there were multiple reports from the same trial, the most complete and/or more recently reported data were chosen.

\section{Data extraction}

Two reviewers (QL \& QXL) evaluated each study separately and extracted data. To assess the outcome, HbA1c levels before and after the intervention were noted. In the event of several post-intervention values, only the first one was considered. Other data extracted was as follows: characteristics of the participants (gender, age, HbA1c value at baseline and enrollment criteria), sample size, intervention mode (described in the following paragraph), frequency of contact, interval between pre- and post-intervention and the theory basis, etc.

Mode of peer support: In order to obtain relevant results for our meta-analysis, we divided peer supporters into two modes namely, 'Community health workers' and 'Peer coaches', based on literature reviews and expert opinions [16,22,24]. (i) Community health workers (CHWs) are members of the local community who serve as bridges between patients and health care providers [28], and they promote health in their communities through information distribution, assistance, social support and organization of community networks [29]. They have not necessarily had diabetes themselves but have been peers to the populations they serve in other important respects: They often speak the local language, share community, culture, and life experiences with their clients $[29,30]$. A number of different terms are used for CHWs including promoters, patient navigators, lay health workers and natural helpers. (ii) Peer coaches, also named as peer educators, peer mentors or peer leaders, are more informal and offer a flexible approach to provide peer support for patients. Peer coaches might be diabetes patients who have successfully coped with diabetes, and also could be those patients who had high HbA1c level and were struggling to bring down their glucose level [31]. 
In addition, frequency of contact was estimated on the basis of the reported intervention protocol and when available, the results. We classified the frequency into three levels: low (less than one contact in a period of one month per patient), moderate (one or two contacts in a period of one month per patient) and high (more than two contacts in a month per patient).

In the event of discrepancies in the data extracted, the same data was subjected to further review by another member of our team (XHY), and the consensus was arrived at.

\section{Assessment of the methodological quality of individual studies}

Two members of our research team (QL \& LQ) assessed each trial independently. We assessed risk of bias using the Cochrane Collaboration's tool (Higgins [32]), regarding the following domains:

Random sequence generation (selection bias);

Allocation concealment (selection bias);

Blinding (performance bias and detection bias) of outcome assessment. Because of the nature of the study design, it seems impossible to blind the participants, thus, blinding of participants was not be used as a criteria for risk of bias evaluation;

Incomplete outcome data (attrition bias);

Selective reporting (reporting bias);

Other bias.

As recommended, we rated each item as: 1) "little risk of bias" if it is completely fulfilled quality standards with the least bias; 2) "unclear" if it is plausible that a bias raises some doubt about the results; and 3) "high risk of bias" if it is plausible that a bias seriously weakens confidence in the results. In cases of disagreement, the rest of the group was consulted, and judgment was made based on consensus. The assessment was not used as a criterion for the selection of trials, whereas some items were used only for descriptive purposes.

\section{Statistical analysis}

Statistical analyses were conducted following the recommendations of the Cochrane Handbook for Systematic Reviews of Interventions and the PRISMA statement. We performed all analyses in Review Manager 5.2 and Stata version 12.1.

The meta-analysis was conducted using a randomeffects model because of the a priori heterogeneity. The $\mathrm{x}^{2}$ and $I^{2}$ statistics were used to assess statistical heterogeneity across studies, with $I^{2}$ values of $50 \%$ or more indicating a substantial level of heterogeneity [32]. To account for differences in baseline HbA1c levels between the studies, we calculated the mean difference between pre- and post-intervention HbA1c levels for the intervention and control groups and the standard deviation (SD) of each difference [33]. Thus, our outcome was the pooled mean difference (MD) in HbA1c levels between the intervention and control groups, along with the 95\% confidence interval (CI). We calculated the SD from reported $P$ values or $\mathrm{CI}$, as recommended by the Cochrane Collaboration or used the imputation method according to baseline values for missing SDs (we imputed missing SDs according to the pre- intervention values) [32,34].

To assess the potential confounding effect of Heterogeneity, subgroup analyses were performed, according to the characteristics of studies, the HbA1c levels of participants at baseline, the mode of peer support, the frequency of contact, and the length of intervention. Funnel plots were drawn, and Egger tests computed to explore a potential publication bias. A $p$ value of less than 0.10 was considered to be statistically significant. A sensitivity analysis was conducted to assess the influence of individual studies on the pooled result, by excluding each study one by one and recalculating the combined $\mathrm{MD}$ on the remaining studies.

\section{Results}

\section{Results of the research and the included studies}

Initially, 3,223 citations were identified (Figure 1). After initial screening of titles and abstracts, 109 potentially relevant full-text articles were reviewed for eligibility. The review included 13 RCTs [17,18,35-45], involving 2,352 participants.

Details of the included studies, comprising of the characteristics of the study (author, country, study setting) and participants (number, enrollment criteria, age, gender and HbA1c level at baseline), the mode of peer support, the characteristic of intervention of the 13 RCTs are shown in Tables 1 and 2 (at the end of the article). Eleven trials were conducted in the United States, one in Vietnam and one in Ireland. Sample sizes ranged from 38 to 352 . The duration of the intervention ranged from 3 to 24 months. The 2,352 participants (63.2\% women) were of a mean age of 57.4 years (45.7 67.7). The mean HbA1c concentration at baseline was 8.2\% (range 6.7 - 10.1).

Patients in nine studies attended structured diabetes education sessions conducted by peer supporters weekly or every 2 weeks ( 6 to 8 times, 2 or 2.5 hours every time), covered areas primarily centered on the recommendation by the American Diabetes Association, including the basics of diabetes and its complications, diet, exercise, medication, blood glucose monitoring etc. $[17,18,39-43,45,46]$. In two of the studies $[39,46]$, patients received individual follow-up by peer supporters to assist them set specific goals and support their progress, after attending all the education sessions. In the other 4 studies [35-38], peer 


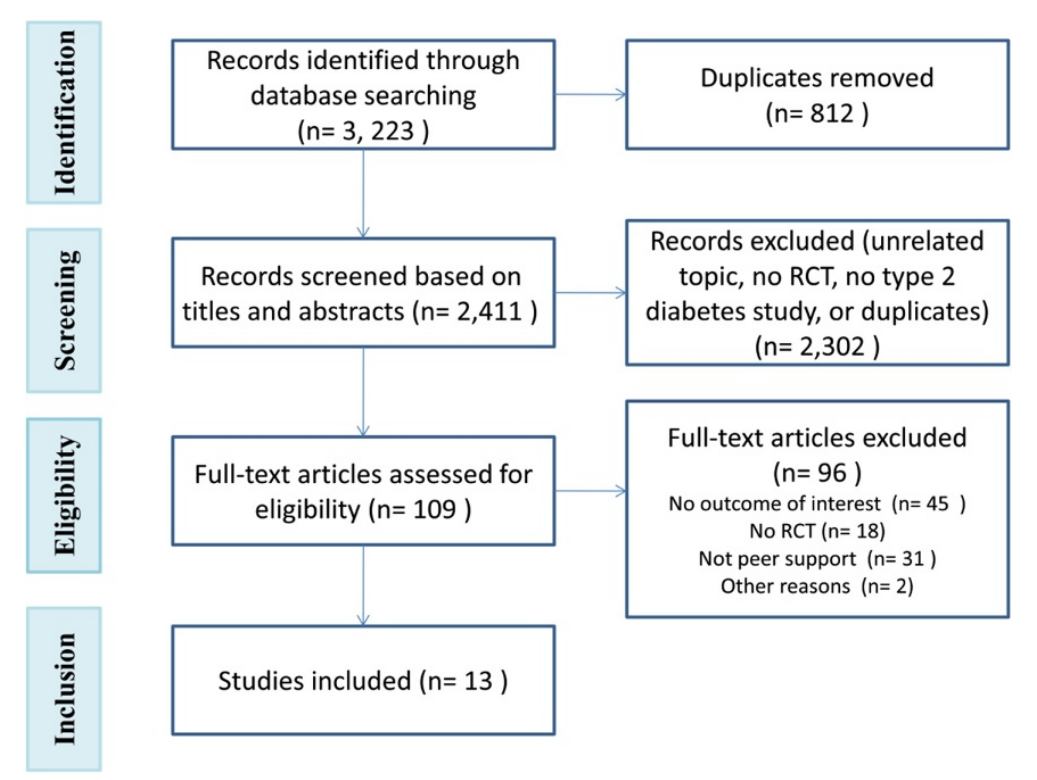

Figure 1 Selection of studies of meta-analysis of peer support interventions.

support provided by individual intervention, covered diabetes self-management skills, providing social and emotional support, assisting with lifestyle change and facilitating medication understanding, etc.

\section{Methodological quality of included studies}

A breakdown of study quality is presented in Additional file 1: Table S1. Overall, out of 13 included studies, eight studies adequately described randomization sequence generation, and were free of selective outcome reporting. Ten studies didn't describe allocation concealment; seven studies didn't describe blinding to outcome assessment. Most studies were not free of other biases (e.g. lack of strict method to avoid participants in usual care group being contaminated by peer support group). A summary of the risk of bias in included studies is presented in Additional file 2: Figure S1 and Additional file 3: Figure S2.

\section{Effect of intervention on glycemic control}

The impact of the peer support programs on changes in HbA1c level in the intervention and control groups is presented in Figure 2. In the random-effect model, the pooled mean difference in levels between the intervention and control groups was -0.57 ( $95 \%$ CI -0.78 to -0.36 ), favoring peer support over usual care. No study reported a significant reduction in $\mathrm{HbA1c}$ in favor of traditional care. There was significant heterogeneity among the trials regarding changes in HbA1c $\left(I^{2}=80.0 \%\right)$.

\section{Subgroup analyses}

We conducted post hoc subgroup analyses to explore possible differences between studies rendering to their characteristics, the HbA1c levels of participants at baseline, the mode and type of peer support, the frequency of contact, and the length of intervention, etc. (Table 3)

The reduction in HbA1c levels were greater among patients with a baseline HbA1c level $\geq 8.5 \%$ (MD -0.78 [-1.06 to -0.51$]$ ) and between $7.5 \sim 8.5 \%$ (MD -0.76 $[-1.05$ to -0.47$])$, than patients with a baseline HbA1c level $<7.5 \%$ which showed no significant reduction in HbA1c levels compared with usual care (MD -0.08 [-0.32 to 0.16]). ( $p<0.05$ for subgroup difference, Additional file 4: Figure S3).

Patients in four studies were provided with individual intervention and responded by a greater reduction in HbA1c level (MD -0.91 [ -1.10 to -0.71$]$ ) in comparison with patients provided with group session education (MD -0.42 [-0.72 to -0.11$]$ ) or a combination of group and individual education (MD $-0.52[-0.66$ to -0.38$]$ ). ( $\mathrm{P}<0.05$ for subgroup difference, Additional file 5: Figure S4).

Programs with a high or moderate frequency of contact reported a significant reduction in HbA1C levels compared with usual care (MD $-0.52[-0.60$ to -0.44$]$ ) and $-0.75[-1.21$ to -0.29$])$. Nevertheless, programs with a low frequency of contact showed no significant reduction in HbA1c level compared with usual care (MD -0.32 [ -0.74 to 0.09 ]; Additional file 6: Figure S5).

We found no major differences in HbA1c levels relative to publication year, the mode of peer support, study location or the duration of intervention (Table 3).

\section{Publication bias and sensitivity analyses}

We explored the possibility of publication bias for the included 13 studies. The funnel plot for the outcome 
Table 1 Characteristics of the included studies: study setting, sample size, and study participants

\begin{tabular}{|c|c|c|c|c|c|c|c|c|c|}
\hline First author and year & Country & Study setting & $\begin{array}{l}\text { Baseline sample } \\
\text { size } \\
\text { (intervention/ } \\
\text { usual care) }\end{array}$ & $\begin{array}{l}\text { End of study } \\
\text { number } \\
\text { (intervention/ } \\
\text { usual care) }\end{array}$ & $\begin{array}{l}\text { Average age } \\
\text { (intervention/ } \\
\text { usual care) }\end{array}$ & $\begin{array}{l}\text { Sex (Female) } \\
\text { (intervention/ } \\
\text { usual care) }\end{array}$ & $\begin{array}{l}\text { Socioeconomic } \\
\text { status }\end{array}$ & Education level & $\begin{array}{l}\text { Average } \mathrm{HbA1c} \\
\text { at baseline (\%) } \\
\text { (intervention/ } \\
\text { usual care) }\end{array}$ \\
\hline Thom 2013 [35] & USA & $\begin{array}{l}\text { Public health } \\
\text { clinics }\end{array}$ & $148 / 151$ & $122 / 114$ & $54.1 / 56.3$ years & $53.0 \% / 51.4 \%$ & Low-income & $\begin{array}{l}\text { 35.6\%: < high school } \\
\text { education }\end{array}$ & $9.84 / 10.14$ \\
\hline Dang 2013 [36] & Vietnam & $\begin{array}{l}\text { Diabetes } \\
\text { outpatient clinic }\end{array}$ & $51 / 51$ & $42 / 44$ & NR & NR & NR & NR & $7.96 / 7.85$ \\
\hline Prezio 2013 [37] & USA & $\begin{array}{l}\text { Community } \\
\text { health services } \\
\text { clinic }\end{array}$ & $90 / 90$ & $78 / 78$ & 47.9/45.7 years & $66.7 \% / 54.4 \%$ & NR & $\begin{array}{l}24.1 \%:<6 \text { years; } 46 \%: 6-11 \\
\text { years; } 29.9 \%: \geq 12 \text { years. }\end{array}$ & $8.9 / 8.7$ \\
\hline Long 2012 [38] & USA & $\begin{array}{l}\text { Philadelphia } \\
\text { Veterans Affairs } \\
\text { Medical Center }\end{array}$ & $39 / 39$ & $38 / 39$ & $60 / 60$ years & $0 / 8 \%$ & NR & $68 \%:<12$ years & $9.8 / 9.9$ \\
\hline Spencer 2011 [39] & USA & 2 Communities & $84 / 99$ & $58 / 69$ & $50 / 55$ year & $75 \% / 61 \%$ & NR & NR & $8.6 / 8.5$ \\
\hline Smith 2011 [17] & Ireland & 20 Practices & $192 / 203$ & $166 / 171$ & $66.1 / 63.2$ years & $46 \% / 46 \%$ & NR & $\begin{array}{l}\text { 41\%: primary education; } 8 \%: \\
\text { third level education }\end{array}$ & $7.2 / 7.2$ \\
\hline Lorig 2009 [18] & USA & Community & $186 / 159$ & $161 / 133$ & $67.7 / 65.4$ years & $62.4 \% / 66.2 \%$ & NR & Mean: $15.9 \pm 2.96$ years & $6.70 / 6.74$ \\
\hline Lorig 2008 [40] & USA & Community & 219/198 & $179 / 173$ & $52.9 / 52.8$ years & $57.1 \% / 67.2 \%$ & NR & Mean: $7.68 \pm 4.49$ years & $7.44 / 7.38$ \\
\hline Murrock 2009 [41] & USA & Community & $24 / 22$ & $20 / 18$ & $58.5 / 67.1$ years & $100 \% / 100 \%$ & NR & NR & $7.7 / 7.4$ \\
\hline Philis-Tsimikas 2011 [42] & USA & $\begin{array}{l}\text { Community } \\
\text { health centers }\end{array}$ & $104 / 103$ & $64 / 81$ & $52.2 / 49.2$ years & $66.3 \% / 74.8 \%$ & $\begin{array}{l}\text { The majority of } \\
\text { participants were } \\
\text { low-income }\end{array}$ & $\begin{array}{l}54.8 \%:<8 \text { years; } 45.2 \%: \\
\geq 8 \text { years }\end{array}$ & $10.5 / 10.3$ \\
\hline Lujan 2007 [43] & USA & $\begin{array}{l}\text { Community } \\
\text { clinic }\end{array}$ & $75 / 75$ & $71 / 70$ & 58 years (total) & $80 \%$ (total) & $\begin{array}{l}42 \%: \leqq \$ 10.000 \\
\text { per year }\end{array}$ & 95\%: < high school education & $8.21 / 7.71$ \\
\hline Samuel-Hodge 2009 [46] & USA & Churches & $117 / 84$ & $102 / 72$ & $57.0 / 61.3$ years & $64 \% / 63 \%$ & $\begin{array}{l}44 \%: \leqq \$ 10.000 \\
\text { per year }\end{array}$ & mean: $12.6 \pm 0.4$ years & $7.7 / 7.9$ \\
\hline Feathers 2005 [45] & USA & $\begin{array}{l}\text { Community } \\
\text { health centers }\end{array}$ & $111 / 98$ & $91 / 98$ & 58.5 years/NR & $79 \% / 79 \%$ & NR & $\begin{array}{l}\text { 43.0\%: < high school; 20.0\%: } \\
\text { high school; 23.0\%: college }\end{array}$ & $8.4 / 8.4$ \\
\hline
\end{tabular}


Table 2 Characteristics of the included studies: characteristics of peer support, frequency, length and theory basis of intervention, and description of usual

\section{care group}

\begin{tabular}{|c|c|c|c|c|c|c|c|c|}
\hline $\begin{array}{l}\text { First author and } \\
\text { year }\end{array}$ & $\begin{array}{l}\text { Mode of } \\
\text { peer } \\
\text { support }\end{array}$ & $\begin{array}{l}\text { Enrollment criteria for Peer coach } \\
\text { or CHW }\end{array}$ & $\begin{array}{l}\text { Training for } \\
\text { peer coach or } \\
\text { CHW }\end{array}$ & Group/Individual & $\begin{array}{l}\text { Frequency of } \\
\text { intervention }\end{array}$ & $\begin{array}{l}\text { Length of } \\
\text { intervention }\end{array}$ & Theory basis & $\begin{array}{l}\text { Description of usual care } \\
\text { group }\end{array}$ \\
\hline Thom 2013 [35] & Peer coach & $\begin{array}{l}\text { T2DM who had an } \mathrm{HbA} 1 \mathrm{c} \text { level of less } \\
\text { than } 8.5 \% \text { within the past } 6 \text { months }\end{array}$ & 36-hour & $\begin{array}{l}\text { Individual } \\
\text { (telephone } \\
\text { contact and in- } \\
\text { person contact) }\end{array}$ & High & 6 months & None & $\begin{array}{l}\text { Usual care included all services } \\
\text { usually available to patients, } \\
\text { including access to a } \\
\text { nutritionist and diabetes } \\
\text { educator through referral from } \\
\text { their primary care clinician. }\end{array}$ \\
\hline Dang 2013 [36] & Peer coach & $\begin{array}{l}\text { T2DM for one year or more, } 30 \text { years } \\
\text { old or older, and with } \mathrm{HbA1c} \text { level in } \\
\text { the most recent three months equal } \\
\text { to or less than } 7 \% \text {. }\end{array}$ & Four sessions & $\begin{array}{l}\text { Individual } \\
\text { (telephone } \\
\text { contact) }\end{array}$ & Moderate & 6 months & $\begin{array}{l}\text { Social cognitive } \\
\text { theory }\end{array}$ & $\begin{array}{l}\text { Follow up at the diabetes } \\
\text { outpatient clinic on different } \\
\text { dates from the participants in } \\
\text { the intervention group to } \\
\text { prevent subject contamination. }\end{array}$ \\
\hline Prezio 2013 [37] & CHW & $\begin{array}{l}\text { Adult female lifelong member of the } \\
\text { local Mexican American community, } \\
\text { with a high school equivalency } \\
\text { (General Educational Development: } \\
\text { GED) and certification from the State } \\
\text { of Texas as a CHW. }\end{array}$ & $27 \mathrm{~h}$ & Individual & Low & 12 months & $\begin{array}{l}\text { Social cognitive } \\
\text { theory }\end{array}$ & Usual medical care. \\
\hline Long 2012 [38] & $\begin{array}{l}\text { Peer coach } \\
\text { or mentors }\end{array}$ & $\begin{array}{l}\text { Diabetes patients whose glucose } \\
\text { control had previously been poor but } \\
\text { was currently good. }\end{array}$ & 1 hour & $\begin{array}{l}\text { Individual } \\
\text { (telephone } \\
\text { contact) }\end{array}$ & Low & 6 months & $\begin{array}{l}\text { Motivational } \\
\text { interviewing } \\
\text { techniques }\end{array}$ & Usual care. \\
\hline Spencer 2011 [39] & CHW & $\begin{array}{l}\text { Family health advocates, from the } 2 \\
\text { participating communities, where they } \\
\text { were ethnically matched with their } \\
\text { assigned participants }\end{array}$ & $\begin{array}{l}\text { more than } \\
80 \text { hours }\end{array}$ & Both & High & 6 months & $\begin{array}{l}\text { Motivational } \\
\text { interviewing and } \\
\text { Empowerment } \\
\text { theory }\end{array}$ & Usual care. \\
\hline Smith 2011 [17] & $\begin{array}{l}\text { Peer } \\
\text { supporter }\end{array}$ & $\begin{array}{l}\text { T2DM for at least one year; adherent } \\
\text { to treatment and behavior change } \\
\text { regimens; Capacity and commitment } \\
\text { to undergo the training required etc. }\end{array}$ & $\begin{array}{l}\text { Two evening } \\
\text { training } \\
\text { sessions }\end{array}$ & Group & Low & 24 months & $\begin{array}{l}\text { Social support } \\
\text { theory }\end{array}$ & $\begin{array}{l}\text { Provided regular recall of } \\
\text { patients every three to six } \\
\text { months with an annual audit } \\
\text { of risk factors. }\end{array}$ \\
\hline Lorig 2009 [18] & $\begin{array}{l}\text { Peer } \\
\text { leaders }\end{array}$ & $\begin{array}{l}\text { Age from } 35 \text { to } 70 \text { years and came } \\
\text { from the same communities as the } \\
\text { participants. Most had type } 2 \text { diabetes } \\
\text { and were not health professionals }\end{array}$ & 4 days & Group & Low & 6 months & None & $\begin{array}{l}\text { Usual care was representative } \\
\text { of care received in urban } \\
\text { areas. }\end{array}$ \\
\hline Lorig 2008 [40] & Peer leader & $\begin{array}{l}\text { Spanish-speaking peer leaders came } \\
\text { from the same communities as the } \\
\text { participants most had type } 2 \text { diabetes } \\
\text { and were not health professionals }\end{array}$ & 4 days & Group & Moderate & 6 months & None & Usual care. \\
\hline \multirow[t]{2}{*}{ Murrock 2009 [41] } & Peer coach & $N R$ & $N R$ & Group & High & 3 months & $\begin{array}{l}\text { Social cognitive } \\
\text { theory }\end{array}$ & $\begin{array}{l}\text { Usual care group continued } \\
\text { with their normal daily } \\
\text { routines, medication schedule, } \\
\text { diet, and glucose-monitoring } \\
\text { regimen. }\end{array}$ \\
\hline & & & & Group & High & 10 months & None & Usual care. \\
\hline
\end{tabular}


Table 2 Characteristics of the included studies: characteristics of peer support, frequency, length and theory basis of intervention, and description of usual care group (Continued)

\begin{tabular}{|c|c|c|c|c|c|c|c|c|}
\hline $\begin{array}{l}\text { Philis-Tsimikas } \\
2011 \text { [42] }\end{array}$ & $\begin{array}{l}\text { Peer } \\
\text { educators }\end{array}$ & $\begin{array}{l}\text { Individuals with diabetes who } \\
\text { exemplified the traits of a natural } \\
\text { leader were identified from the } \\
\text { patient population and trained as } \\
\text { promotoras over a 3-month period }\end{array}$ & $\begin{array}{l}40 \text { h learning, } 2 \\
\text { series of classes } \\
\text { and then finally } \\
\text { taught two } \\
\text { series on their } \\
\text { own. }\end{array}$ & & & & & \\
\hline Lujan 2007 [43] & $\begin{array}{l}\text { Peer } \\
\text { promotoras }\end{array}$ & NR & 60 hours & Group & High & 6 months & $\begin{array}{l}\text { Community } \\
\text { empowerment }\end{array}$ & $\begin{array}{l}\text { Usual one-on-one patient } \\
\text { education by the clinic staff } \\
\text { during scheduled medical } \\
\text { follow-up visits, which } \\
\text { consisted of verbal information } \\
\text { and } 1 \text { or } 2 \text { pamphlets on } \\
\text { diabetes self-management } \\
\text { skills. }\end{array}$ \\
\hline $\begin{array}{l}\text { Samuel-Hodge } \\
2009[46]\end{array}$ & $\begin{array}{l}\text { Peer } \\
\text { counselor }\end{array}$ & $\begin{array}{l}\text { T2DM or having lived with someone } \\
\text { diagnosed with diabetes for at least } \\
2 \text { years }\end{array}$ & $\begin{array}{l}\text { over a 1-month } \\
\text { period (4 } \\
\text { weekly 4-hour } \\
\text { sessions) }\end{array}$ & Both & High & 8 months & None & $\begin{array}{l}\text { Received standard educational } \\
\text { pamphlets by mail. }\end{array}$ \\
\hline $\begin{array}{l}\text { Feathers } 2005 \\
\text { [45] }\end{array}$ & CHW & $\begin{array}{l}\text { African American and Latino } \\
\text { community residents }\end{array}$ & 10 weeks & Group & Low & 10 months & NR & Usual care. \\
\hline
\end{tabular}

CHW: community health worker, NR: not reported. 


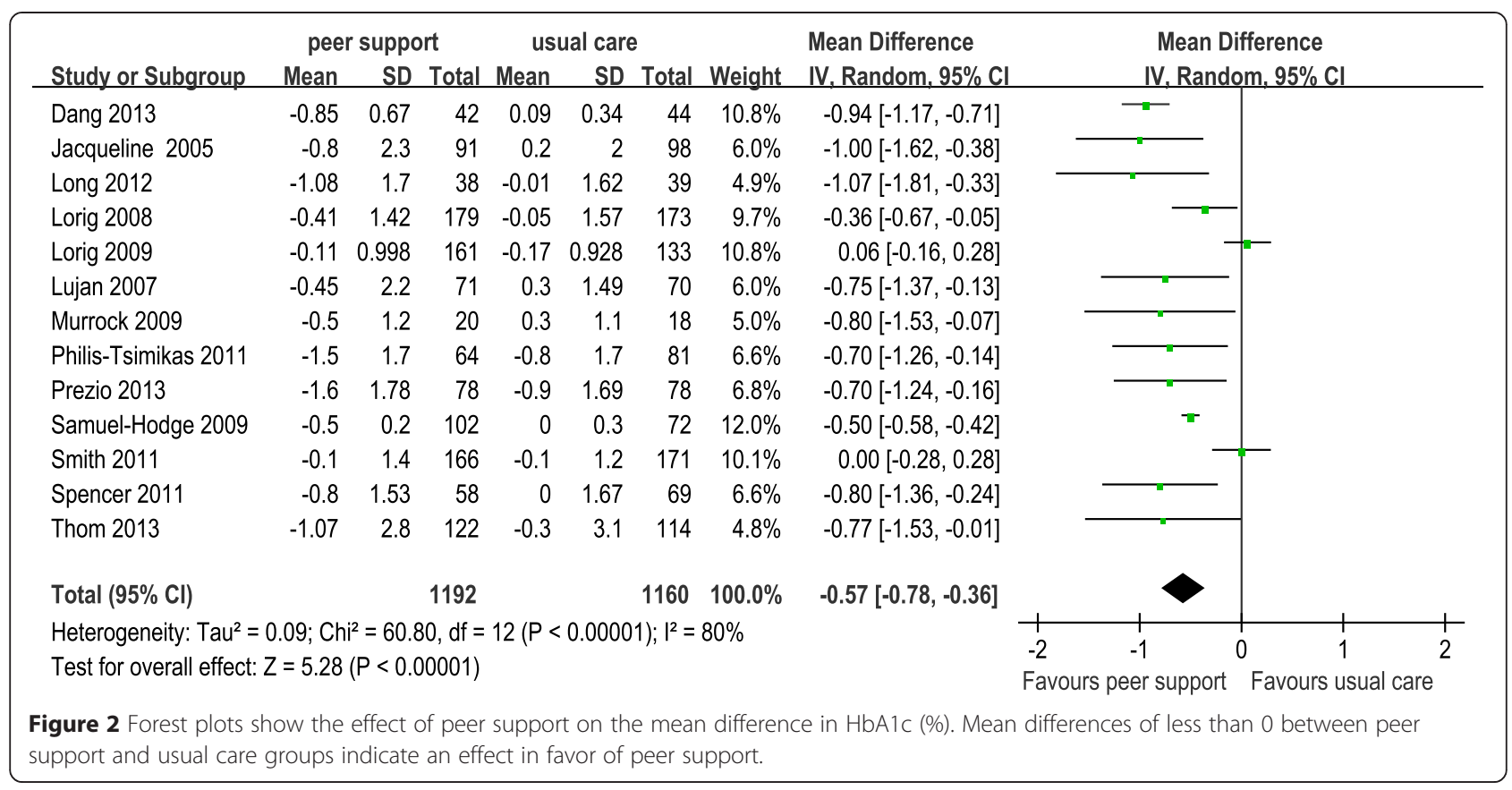

HbA1c showed a slight asymmetry, using the Egger test $(P=0.014)$, indicating a potential publication bias (Additional file 7: Figure S6).

In order to investigate the reliability of the results, we analyzed their sensitivity. After excluding each of the studies one at a time, the analyses did not detect any influence of one single study on the overall results (Additional file 8: Figure S7).

\section{Discussions}

Our meta-analysis suggested that peer support has a favorable effect on improving glycemic control, with a pooled mean reduction of $0.57 \%$ in HbA1c levels compared with usual care. This study has important implications for current clinical and public health practice and research. Glycaemic control is an important predictor of many of the chronic complications of diabetes $[47,48]$. According to the UK Prospective Diabetes Study, each $1 \%$ reduction in HbA1c over 10 years is associated with reductions in risk of up to $21 \%$ for any end point related to diabetes, $21 \%$ for deaths related to diabetes, $14 \%$ for myocardial infarctions and $37 \%$ for micro-vascular complications [48]. Thus, the improvement in $\mathrm{HbA} 1 \mathrm{c}$ of $0.57 \%$ is clinically significant. Moreover, this finding are probably underestimated because the usual care provided in control groups in RCTs is often better than that provided in clinical practice. Some studies included in our meta-analysis permitted patients in the control group to contact the medical team or be contacted by them during follow-up in addition to usual care $[17,35,43]$.
Our findings showed that peer support is more effective for patients who have poor glycemic control (mean HbA1c $\geq 7.5 \%$ at baseline) than for those with better glycemic control. These results might be partly because patients with lower HbA1c levels at baseline had already reached a floor effect, leaving little room for improvement after intervention. Thus, peer support could be particularly effective if targeted at patients with non-stabilized diabetes. It is worth mentioning that such patients have a higher risk of developing complications and so would probably derive greater long-term benefits from peer support.

Of the 13 included RCTs, most were peer-led group self-management education rather than individual intervention. To date, many peer-led group intervention programs followed a model that was first developed and evaluated by Kate Lorig et al. (http://patienteducation. stanford.edu): the Chronic Disease Self-Management Program (CDSMP). The CDSMP is a program for patients with different chronic conditions including diabetes given in 2.5-hour sessions once a week over 6 weeks. Peer supporters offer the courses in an interactive manner designed to enhance participants' confidence in their ability to execute specific self-care tasks. Compared with traditional CDSMP led by professionals, peer-led interventions are more easily held outside of normal working hours, allowing more courses to be offered at varying times. The results indicated the effectiveness of peer-led group self-management education, with a significant decrease of mean HbA1c value of $-0.42 \%$. However, some participants face challenges in attending structured face-to-face meetings, and it was also 
Table 3 Subgroup analyses for the difference in HbA1c with peer support compared with usual care group

\begin{tabular}{|c|c|c|c|c|}
\hline \multirow[t]{2}{*}{ Study characteristics } & \multirow{2}{*}{$\begin{array}{l}\text { No. of } \\
\text { studies }\end{array}$} & \multirow{2}{*}{$\begin{array}{l}\text { Mean difference of } \\
\text { HbA1c, \% }(95 \% \mathrm{Cl})\end{array}$} & \multicolumn{2}{|c|}{ Heterogeneity } \\
\hline & & & $\mathrm{P}$ & $I^{2}(\%)$ \\
\hline All studies & 13 & $-0.57(-0.78$ to -0.36$)$ & $<0.0001$ & 80.0 \\
\hline \multicolumn{5}{|l|}{ Publication year } \\
\hline Before 2010 & 6 & $-0.47(-0.76$ to -0.17$)$ & $<0.0001$ & 82.0 \\
\hline After 2011 & 7 & $-0.68-1.05$ to -0.31$)$ & $<0.0001$ & 79.0 \\
\hline \multicolumn{5}{|l|}{ Study location } \\
\hline Medical institution & 8 & $-0.71(-1.05$ to -0.37$)$ & $<0.0001$ & 77.0 \\
\hline Community or church & 5 & $-0.41(-0.71$ to -0.10$)$ & $<0.0001$ & 84.0 \\
\hline \multicolumn{5}{|l|}{ HbA1c level at baseline* } \\
\hline$\geq 8.5 \%$ & 5 & $-0.78(-1.06$ to -0.51$)$ & 0.94 & 0.0 \\
\hline $7.5 \%$ to $8.5 \%$ & 5 & $-0.76(-1.05$ to -0.47$)$ & 0.003 & 75.0 \\
\hline$<7.5 \%$ & 3 & $-0.08(-0.32$ to 0.16$)$ & 0.09 & 59.0 \\
\hline \multicolumn{5}{|l|}{ Mode of peer support } \\
\hline Peer coach & 10 & $-0.51(-0.75$ to -0.27$)$ & $<0.0001$ & 84.0 \\
\hline Community health worker & 3 & $-0.82(-1.15$ to -0.49$)$ & 0.92 & 0.0 \\
\hline \multicolumn{5}{|l|}{ Type of peer support ${ }^{*}$} \\
\hline Individual & 4 & $-0.91(-1.10$ to -0.71$)$ & 0.81 & 0.0 \\
\hline Group & 7 & $-0.42(-0.72$ to -0.11$)$ & 0.0006 & 74.0 \\
\hline Both & 2 & $-0.52(-0.66$ to -0.38$)$ & 0.30 & 8.0 \\
\hline \multicolumn{5}{|l|}{ Frequency of contact } \\
\hline High & 6 & $-0.52(-0.60$ to -0.44$)$ & 0.68 & 0.0 \\
\hline Moderate & 3 & $-0.75(-1.21$ to -0.29$)$ & 0.009 & 79.0 \\
\hline Low & 4 & $-0.32(-0.74$ to 0.09$)$ & 0.002 & 80.0 \\
\hline \multicolumn{5}{|l|}{ Length of intervention } \\
\hline$\leqq 6$ months & 8 & $-0.64(-1.01$ to -0.27$)$ & $<0.0001$ & 85.0 \\
\hline$>6$ months & 5 & $-0.51(-0.81$ to 0.20$)$ & 0.004 & 74.0 \\
\hline
\end{tabular}

Note: $\mathrm{Cl}=$ confidence interval; ${ }^{*} \mathrm{p}<0.05$ (subgroup difference).

difficult to summon all the participants together at the same time.

In addition to group intervention programs, there were some individual peer-led interventions, which seem more informal and flexible than structured group interventions. By individual intervention, peer supporters meet other patients and listen, discuss concerns and provide support to them. These peer supporters usually receive initial training of 8 to 32 hours with the training focusing on communication skills, including empathic listening, helping participants clarify their values and life goals, problem-solving and assertiveness. The results of our meta-analysis showed that the individual intervention might be more effective than structured group intervention and group education followed by individual on-going support. Moreover, three of the four peer-led individual intervention RCTs were conducted by telephone, which is helpful in avoiding distance barriers and allows for frequent contact with patients at a lower cost. Therefore, if carefully designed and implemented, telephone-based peer support might be a satisfactory choice for diabetes management and should be introduced on a large scale.

In order to explore the effect of program intensity on its effectiveness, we explored the length of intervention and the frequency of patients' contact. We didn't find any significant variance linked to the length of intervention; however, the frequency of contact seemed to be a key feature of the effectiveness. Peer support with low frequency of contact showed no significant change on its effectiveness, whereas moderate and high frequency of contact pointed to a significant improvement of glycemic control. This result means that only peer-support with moderate or intensive intervention should be implemented. We also explored the mode of peer support on the programme's effectiveness but didn't find any significant difference between the impact of community health workers or peer coaches. Thus, both of them could be potential peer supporters based on the different settings and populations.

The strengths of the study included a comprehensive, systematic review of the literature; we used a broad search 
strategy to capture all relevant information. Furthermore, we included only RCTs and several recent studies. Therefore, our estimate is probably more precise than that in previous studies.

Our study, nonetheless, has some limitations. Firstly, a high level of statistical heterogeneity was noted in our review. Therefore, we conducted subgroup analyses to explore it and used random-effect model that enabled heterogeneity to be accounted for in the analysis. However, it is hard to conduct sub-group analysis for the socioeconomic status and the educational level of the participants due to the insufficient information, which indicate that information on the socioeconomic status and education level of participants should be reported in future trials. Secondly, as in all meta-analysis, the possibility of publication bias and selection bias is of concern. Thirdly, the number of studies on CHWs is limited, further epidemiological studies are needed to be done to accumulate more evidence. Finally, most of the studies met our inclusion criteria conducted in the United States, which might influence the generalizability of the findings to other types of geographic areas.

\section{Conclusions}

In conclusion, peer support models provide a potentially flexible means for diabetes self-management education or on-going support programs. Practical components need a moderate or high frequency of patient contact with targeted patients those of poor glycemic control. Priority should be given to programs with moderate or high contact of target patients, with poor glycemic control, rather than programs with low frequency of patients' contact that target the overall population of patients with T2DM. In addition, more telephone-based peer support programs are needed to explore the long-term efficacy on glycemic control.

Considering most of the included studies were implemented in USA and were at a potential risk of bias, as many studies were rated as 'unclear' because of a lack of information, especially on allocation concealment, blinding to outcomes data and other biases (e.g. strict methods to avoid participants in usual care group being contaminated by peer support), all of which might reduce the internal validity of the studies. Therefore, well-designed highquality trials are needed to demonstrate the efficacy of peer support in different settings, especially in low-income countries.

\section{Additional files}

Additional file 1: Table S1. Risk of bias of included studies (ordered by study ID).

Additional file 2: Figure S1. Risk of the bias summary: review authors' judgments about each risk of bias item for each included study.
Additional file 3: Figure S2. Risk of bias graph: review authors' judgments about each risk of bias item presented as percentages across all included studies.

Additional file 4: Figure S3. Forest plots show the effect of peer support on the mean difference in $\mathrm{HbA1c}(\%)$ by different $\mathrm{HbA} 1 \mathrm{c}$ level at baseline.

Additional file 5: Figure S4. Forest plots show the effect of peer support on the mean difference in HbA1c (\%) by different type of peer support.

Additional file 6: Figure S5. Forest plots show the effect of peer support on the mean difference in HbA1c (\%) by different frequency of peer support.

Additional file 7: Figure S6. Funnel plot of meta-analysis of the effect of peer support on the mean difference in $\mathrm{HbA1c}$ level among patients with type 2 diabetes.

Additional file 8: Figure S7. Sensitivity analysis (leave-one-out) of meta-analysis of the effect of peer support on the mean difference in HbA1c level among patients with type 2 diabetes.

\section{Competing interests}

The authors declare that they have no competing interests.

\section{Authors' contributions}

QL, XHY, LQ and TWG conceived the idea for the meta-analysis and were guarantors of the overall content. QL and QXL selected and retrieved relevant papers. QL, LQ and WN assessed each trial while $\mathrm{QL}$ and $\mathrm{XHY}$ performed the statistical analysis and drafted the manuscript. All authors revised and approved the final manuscript.

\section{Acknowledgements}

This study was funded by Chongqing Health and Family Planning Commission (Topic No: 20141027) and Chongqing Health Bureau (Topic No: 2012-2-233). We extend our appreciation to Xiangyu Ma, Yao Zhang and Qingyun Liu for their help and advice in the early stages of the review.

\section{Author details}

${ }^{1}$ Department of Military Epidemiology, College of Military Prevention, Third Military Medical University, Chongqing, China. ${ }^{2}$ Chongqing Municipal Center for Disease Control and Prevention, Chongqing, China. ${ }^{3}$ School of Public Health and Management, Chongqing Medical University, Chongqing, China. ${ }^{4}$ Department of Dental Medicine, Sichuan University, Chengdu, China.

Received: 17 January 2015 Accepted: 22 April 2015

Published online: 06 May 2015

\section{References}

1. Zimmet PZ, Magliano DJ, Herman WH, Shaw JE. Diabetes: a 21st century challenge. Lancet Diabetes Endocrinol. 2014;2(1):56-64.

2. Shaw JE, Sicree RA, Zimmet PZ. Global estimates of the prevalence of diabetes for 2010 and 2030. Diabetes Res Clin Pract. 2010;87(1):4-14.

3. Glasgow RE, Funnell MM, Bonomi AE, Davis C, Beckham V, Wagner EH. Self-management aspects of the improving chronic illness care breakthrough series: implementation with diabetes and heart failure teams. Ann Behav Med. 2002;24(2):80-7.

4. Fisher EB, Brownson CA, OToole ML, Shetty G, Anwuri W, Glasgow RE. Ecological approaches to self-management: the case of diabetes. Am J Public Health. 2005;95(9):1523-35.

5. Ricci-Cabello I, Ruiz-Perez I, Rojas-Garcia A, Pastor G, Rodriguez-Barranco M, Goncalves DC. Characteristics and effectiveness of diabetes selfmanagement educational programs targeted to racial/ethnic minority groups: a systematic review, meta-analysis and meta-regression. BMC Endocr Disord. 2014;14:60.

6. Forjuoh SN, Ory MG, Jiang L, Vuong AM, Bolin JN. Impact of chronic disease self-management programs on type 2 diabetes management in primary care. World J Diabetes. 2014;5(3):407-14.

7. Bodenheimer T, Pham HH. Primary care: current problems and proposed solutions. Health Aff (Millwood). 2010;29(5):799-805.

8. Gazmararian JA, Ziemer DC, Barnes C. Perception of barriers to self-care management among diabetic patients. Diabetes Educ. 2009;35(5):778-88. 
9. Dennis CL. Peer support within a health care context: a concept analysis. Int J Nurs Stud. 2003:40(3):321-32.

10. Malchodi CS, Oncken C, Dornelas EA, Caramanica L, Gregonis E, Curry SL. The effects of peer counseling on smoking cessation and reduction. Obstet Gynecol. 2003;101(3):504-10.

11. Mastroleo NR, Oakley WC, Eaton EM, Borsari B. Response of heavy-drinking voluntary and mandated college students to a peer-led brief motivational intervention addressing alcohol use. J Subst Abuse Treat. 2014;47(5):321-8.

12. Small N, Blickem C, Blakeman T, Panagioti M, Chew-Graham CA, Bower P. Telephone based self-management support by 'lay health workers' and 'peer support workers' to prevent and manage vascular diseases: a systematic review and meta-analysis. BMC Health Serv Res. 2013;13:533.

13. Schneider JA, Zhou AN, Laumann EO. A new HIV prevention network approach: sociometric peer change agent selection. Soc Sci Med. 2015;125(1):192-202.

14. Cordero Coma J. HIV prevention and marriage: peer group effects on condom use acceptability in rural Kenya. Soc Sci Med. 2014;116:169-77.

15. Abendroth M, Greenblum CA, Gray JA. The value of peer-led support groups among caregivers of persons with Parkinson's disease. Holist Nurs Pract. 2014;28(1):48-54

16. Funnell MM. Peer-based behavioural strategies to improve chronic disease self-management and clinical outcomes: evidence, logistics, evaluation considerations and needs for future research. Fam Pract. 2010;27 Suppl 1:i17-22.

17. Smith SM, Paul G, Kelly A, Whitford DL, O'Shea E, O'Dowd T. Peer support for patients with type 2 diabetes: cluster randomised controlled trial. BMJ. 2011;342:d715

18. Lorig K, Ritter PL, Villa FJ, Armas J. Community-based peer-led diabetes self-management: a randomized trial. Diabetes Educ. 2009;35(4):641-51.

19. Norris SL, Chowdhury FM, Van Le K, Horsley T, Brownstein JN, Zhang X, et al. Effectiveness of community health workers in the care of persons with diabetes. Diabet Med. 2006;23(5):544-56.

20. Tricia S, Tang GXA, Cherrington A, Gurpreet R. A review of volunteerbased peer support interventions in diabetes. Diabetes Spectrum. 2011;24(2):85-98.

21. Dale J, Caramlau IO, Lindenmeyer A, Williams SM. Peer support telephone calls for improving health. Cochrane Database Syst Rev. 2008;4:CD006903.

22. Dale JR, Williams SM, Bowyer $\mathrm{V}$. What is the effect of peer support on diabetes outcomes in adults? A systematic review. Diabet Med. 2012;29:1361-77.

23. Heisler M. Overview of peer support models to improve diabetes selfmanagement and clinical outcomes. Diabetes Spectrum. 2007;20(4):214-21.

24. Heisler M. Different models to mobilize peer support to improve diabetes self-management and clinical outcomes: evidence, logistics, evaluation considerations and needs for future research. Fam Pract. 2010;27 Suppl 1:i23-32

25. Liberati A, Altman DG, Tetzlaff J, Mulrow C, Gotzsche PC, loannidis JP, et al. The PRISMA statement for reporting systematic reviews and meta-analyses of studies that evaluate healthcare interventions: explanation and elaboration BMJ. 2009;339:b2700.

26. Barton $\mathrm{S}$. Which clinical studies provide the best evidence? The best RCT still trumps the best observational study. BMJ. 2000;321(7256):255-6.

27. Nathan DM, Turgeon H, Regan S. Relationship between glycated haemoglobin levels and mean glucose levels over time. Diabetologia. 2007:50(11):2239-44

28. Witmer A, Seifer SD, Finocchio L, Leslie J, O'Neil EH. Community health workers: integral members of the health care work force. Am J Public Health. 1995:85(8 Pt 1):1055-8.

29. Shah M, Kaselitz E, Heisler M. The role of community health workers in diabetes: update on current literature. Curr Diab Rep. 2013;13(2):163-71.

30. Davis KL, O'Toole ML, Brownson CA, Llanos P, Fisher EB. Teaching how, not what: the contributions of community health workers to diabetes self-management. Diabetes Educ. 2007;33 Suppl 6:208S-15.

31. Heisler M, Vijan S, Makki F, Piette JD. Diabetes control with reciprocal peer support versus nurse care management: a randomized trial. Ann Intern Med. 2010;153(8):507-15.

32. Green JPHaS. Cochrane handbook for systematic reviews of interventions. Version 5.1.0 [updated March 2011]. The Cochrane Collaboration. Available from http://handbook.cochrane.org/.

33. DerSimonian R, Laird N. Meta-analysis in clinical trials. Control Clin Trials. 1986;7(3):177-88
34. Pimouguet $C$, Le Goff M, Thiebaut R, Dartigues JF, Helmer C. Effectiveness of disease-management programs for improving diabetes care: a meta-analysis. CMAJ. 2011;183(2):E115-27.

35. Thom DH, Ghorob A, Hessler D, De Vore D, Chen E, Bodenheimer TA Impact of peer health coaching on glycemic control in low-income patients with diabetes: a randomized controlled trial. Ann Fam Med. 2013;11(2):137-44.

36. Thanh Tran Ngoc Dang WD, Keeratiyutawong P, Baumann L. Effectiveness of a diabetes self-management support intervention in Vietnamese adults with type 2 diabetes. J Sci Technol Humanit. 2013;11(2):13-23.

37. Prezio EA, Cheng D, Balasubramanian BA, Shuval K, Kendzor DE, Culica D. Community diabetes education (CoDE) for uninsured Mexican Americans: a randomized controlled trial of a culturally tailored diabetes education and management program led by a community health worker. Diabetes Res Clin Pract. 2013;100(1):19-28.

38. Long ECJ JA, Richardson DM, Loewenstein G, Volpp KG. Peer mentoring and financial incentives to improve glucose control in African American veterans. Ann Intern Med. 2012;156:416-24.

39. Spencer MS, Rosland AM, Kieffer EC, Sinco BR, Valerio M, Palmisano G, et al. Effectiveness of a community health worker intervention among African American and Latino adults with type 2 diabetes: a randomized controlled trial. Am J Public Health. 2011;101(12):2253-60.

40. Lorig K, Ritter PL, Villa F, Piette JD. Spanish diabetes self-management with and without automated telephone reinforcement: two randomized trials. Diabetes Care. 2008;31(3):408-14.

41. Murrock CJ, Higgins PA, Killion C. Dance and peer support to improve diabetes outcomes in African American women. Diabetes Educ. 2009;35(6):995-1003.

42. Philis-Tsimikas A, Fortmann A, Lleva-Ocana L, Walker C, Gallo LC. Peer-led diabetes education programs in high-risk Mexican Americans improve glycemic control compared with standard approaches: a project dulce promotora randomized trial. Diabetes Care. 2011;34(9):1926-31.

43. Lujan J, Ostwald SK, Ortiz M. Promotora diabetes intervention for Mexican Americans. Diabetes Educ. 2007:33(4):660-70

44. Dale J, Caramlau I, Sturt J, Friede T, Walker R. Telephone peer-delivered intervention for diabetes motivation and support: the telecare exploratory RCT. Patient Educ Couns. 2009;75(1):91-8.

45. Two Feathers J, Kieffer EC, Palmisano G, Anderson M, Sinco B, Janz N, et al. Racial and Ethnic Approaches to Community Health (REACH) Detroit partnership: improving diabetes-related outcomes among African American and Latino adults. Am J Public Health. 2005;95(9):1552-60.

46. Samuel-Hodge CD, Keyserling TC, Park S, Johnston LF, Gizlice Z, Bangdiwala SI. A randomized trial of a church-based diabetes self-management program for African Americans with type 2 diabetes. Diabetes Educ. 2009;35(3):439-54.

47. Zoungas S, Chalmers J, Ninomiya T, Li Q, Cooper ME, Colagiuri S, et al. Association of $\mathrm{HbA} 1 \mathrm{c}$ levels with vascular complications and death in patients with type 2 diabetes: evidence of glycaemic thresholds. Diabetologia. 2012;55(3):636-43.

48. Stratton IM, Adler Al, Neil HA, Matthews DR, Manley SE, Cull CA, et al. Association of glycaemia with macrovascular and microvascular complications of type 2 diabetes (UKPDS 35): prospective observational study. BMJ. 2000;321(7258):405-12.

\section{Submit your next manuscript to BioMed Central and take full advantage of:}

- Convenient online submission

- Thorough peer review

- No space constraints or color figure charges

- Immediate publication on acceptance

- Inclusion in PubMed, CAS, Scopus and Google Scholar

- Research which is freely available for redistribution 